\title{
Constructing mental diagrams during problem-solving in mathematics
}

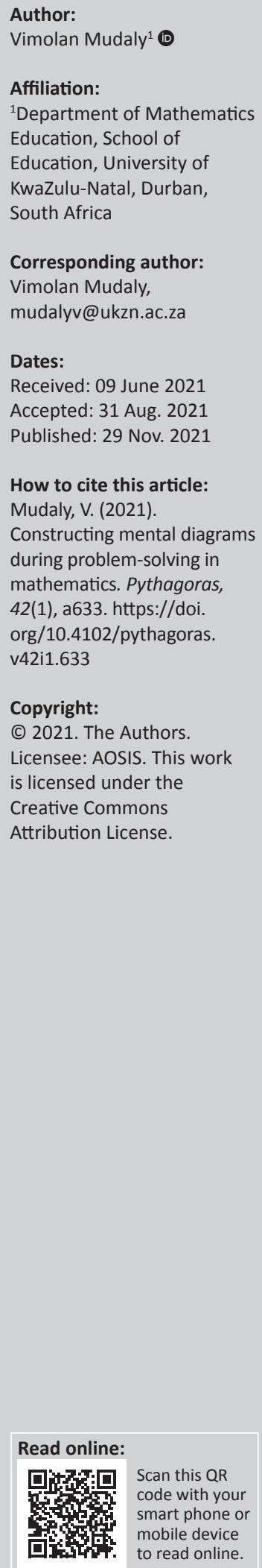

\begin{abstract}
In mathematics, problem-solving can be considered to be one of the most important skills students need to develop, because it allows them to deal with increasingly intricate mathematical and real-life issues. Often, teachers attempt to try to link a problem with a drawn diagram or picture. Despite these diagrams, whether given or constructed, the student still individually engages in a private discourse about the problem and its solution. These discourses are strongly influenced by their a priori knowledge and the given information in the problem itself. This article explores first-year pre-service teachers' mental problemsolving skills. The emphasis was not on whether they solved the problems, but rather on their natural instincts during the problem-solving process. The research shows that some students were naturally drawn to construct mental images during the problem-solving process while others were content to simply leave the question blank. The data were collected from 35 firstyear volunteer students attending a second semester geometry module. The data were collected using task sheets on Google Forms and interviews, which were based on responses to the questions. An interpretive qualitative analysis was conducted in order to produce deeper meaning (insight). The findings point to the fact that teachers could try to influence how students think during the problem-solving process by encouraging them to engage with mental images.
\end{abstract}

Keywords: mathematical images; mental manipulations; problem-solving; visualisation

\section{Introduction}

Solving mathematical problems is generally a useful way to develop a deeper understanding of difficult concepts. But mathematical problems are difficult for most students, as was affirmed by Tambychika and Meerah (2010, p. 142) when they cited students who stated that 'Mathematics problems are really difficult. I did not know how to do it. That's why I did not finish it. I don't like Maths'. This is not new or unique. There is a general tendency to despise what cannot be done easily and problem-solving falls well within this category. Students often struggle with various aspects of a problem and much has been written in this field. Despite all the research 'students' problem-solving skills still require substantial improvement' and the 'one challenge that we have to grasp in our classroom practices is reversing this situation by helping students construct their mathematical knowledge with problem solving' (Vale \& Barbosa, 2018, p. 23).

Guzman (2018, p. 53) acknowledged that 'problem-solving has a special importance in the study of mathematics' and further explained that 'it can also be used, as a teaching method, for a deeper understanding of concepts'. The latter is perhaps a significant function of problem-solving. To achieve understanding of concepts through problem-solving is not an easy process. There are often complex steps that need to be followed and these need to be practised through constant use. Yin (2010, p. 2) also felt that the ability to solve problems 'is at the heart of mathematics' but was convinced that 'visualization is at the heart of mathematical problem solving'. This is indeed significant and forms much of the argument around which data are presented in this article. Walker, Winner, Hetland, Simmons and Goldsmith (2010) also mention that the principles and standards for school mathematics and the common core standards:

explicitly describe visualization as a tool for problem-solving and also recognize the essential role of being able to represent and interpret mathematical ideas and problems in visual forms, including graphs, sketches, and diagrams. (p. 22)

Vale and Barbosa (2018) also found that:

recent research in the area of cognition in particular about problem solving processes, indicates that for certain types of tasks, the use of strategies that requires visual representations may have advantages over the use of other representations, facilitating problem solving. (p. 24) 
Yin (2010) further cited two important passages from the Singapore Ministry of Education (MOE) website, which allude to the possibilities that visualisation offers during the problem-solving process:

Visualization is the ability to see and understand a problem situation. Visualizing a situation or an object involves mentally manipulating various alternatives for solving a problem related to a situation or object without benefit of concrete manipulatives'. (MOE, 2001, p. 51, cited in Yin, 2010, p. 2)

Visualization can be a powerful cognitive tool in problem solving. (MOE, 2007, p. 13, cited in Yin, 2010, p. 2)

These citations capture the essence of visualisation and convey, without any ambiguity, that visualisation involves more than just seeing. It is deeper and involves mental processes. Whiteley (2004, p. 1) stated from his own experiences and collected anecdotes that it is an illusion that mathematical reasoning is done in the brain with language'. So, if it is not done using language, how do we engage with mathematical reasoning in the brain? There is the allusion to the idea that much of our mental reasoning occurs using visual representations and manipulations. This is not easy. Again, Whiteley (2004, p. 3) postulated that 'we create what we see. Visual reasoning or "seeing to think" is learned. It can also be taught and it is important to teach it'.

So what are these mental representations? Chi (2008, p. 67) captured this deftly by describing a mental model as an internal representation of a concept (such as square) or an inter-related system of concepts (such as the quadrilaterals) that corresponds in some way to the external structure that it represents. Ibrahim and Rebello (2013, p. 1) also emphasised this idea of mental representations by claiming that 'a key aspect of teaching and learning requires that the learner visualize, i.e., form images both internally (mentally) and externally (with paper and pencil or technology)'. They further surmised that the:

importance of external representation lies in the fact that it may provide an associated "mental image" of the physical processes in terms of principles and underlying concepts being considered, hence supporting comprehension. (Ibrahim \& Rebello, 2013, p. 1)

Walker et al. (2010, p. 22) also suggested that 'the ability to visualize what cannot be seen directly is considered a critical skill in mathematics and science'. Their claim that visualisation is a critical skill is, in a sense, supported by an argument drawn from the arts. They found that visualisation:

seems to be a fundamental habit of the artistic mind. Artists do not just magically 'see' in their mind's eye, but deliberately and systematically analyze shape and space into familiar simple forms, construction lines, angles, and size ratios. (Walker et al., 2010, p. 23)

This is an analogous argument for the way visualisation is used in mathematics understanding as well. Rösken and Rolka (2006, p. 1) found in their study that 'students that do not show visualization on their paper were able to solve problems correctly. This highlights once again the importance of pictures in the mind'. This is probably the heart of the ability to solve mathematical problems - the ability to manipulate images in the mind. Gutiérrez, Ramírez, Benedicto, Beltrán-Meneu and Jaime (2018, p. 4) noted important elements of visualisation. Significant among them were mental images, external representations and the process of visualisation. They defined mental images as 'any kind of cognitive representation of a mathematical concept or property by means of visual or spatial elements' (Gutiérrez et al., 2018, p. 4). External representations are 'any kind of verbal or graphical representation of concepts or properties including pictures, drawings, diagrams, etc. that helps to create or transform mental images and to do visual reasoning' (Gutiérrez et al., 2018, p. 4). The process of visualisation is 'a mental or physical action where mental images are involved' (Gutiérrez et al., 2018, p. 4). This would imply that every physical action is somehow related to a visualisation process because it would be difficult to conceive of a process where no mental action occurred without a mental image. This image may be in the form of a picture, diagram, icon, symbol, word and so on. Presmeg (1986, p. 42) affirmed this idea when she stated that 'after all, diagrams are a frequent accompaniment to mathematical thinking'.

\section{Theoretical framework}

This article uses the iterative visualisation thinking cycle. The cycle begins with the learner engaging in a physical or visualisation activity (doing stage). The stage is characterised by visualisation of physical or mental activities. The physical activity may involve the use of a manipulative. But despite the physical engagement, all activities are related to some mental activity - they happen in the head - since the hands move as dictated to by the brain. The visual mediators (symbols, graphs, notations, images, and so on) also influence the visualisation activities that occur in the mind. This process of engaging physically (using manipulatives) and mentally is the meaning making stage. Physical and mental objects are manipulated in order to create deeper understanding. The process is iterative because it allows for postulations and testing. If the hypothesis is correct then it is easy to move ahead, but if the hypothesis is shown to be incorrect then the process will start again but with added information (of what does not work and what new information should be employed). In this visualisation process the tendency is eventually to 'see' the concept. 'Seeing' is translated to understanding. Once the concept is understood well ('I got it'), it needs to be converted into a mathematical, symbolic form. Through this process new knowledge is formed or old knowledge is transformed.

\section{Research focus}

The study focuses on the way students conduct selfdiscourses with themselves as they work through a problem in mathematics. This is an attempt at trying to ascertain what students think and how they think, as they work through a mathematics problem from the perspective of the visualisation process. 


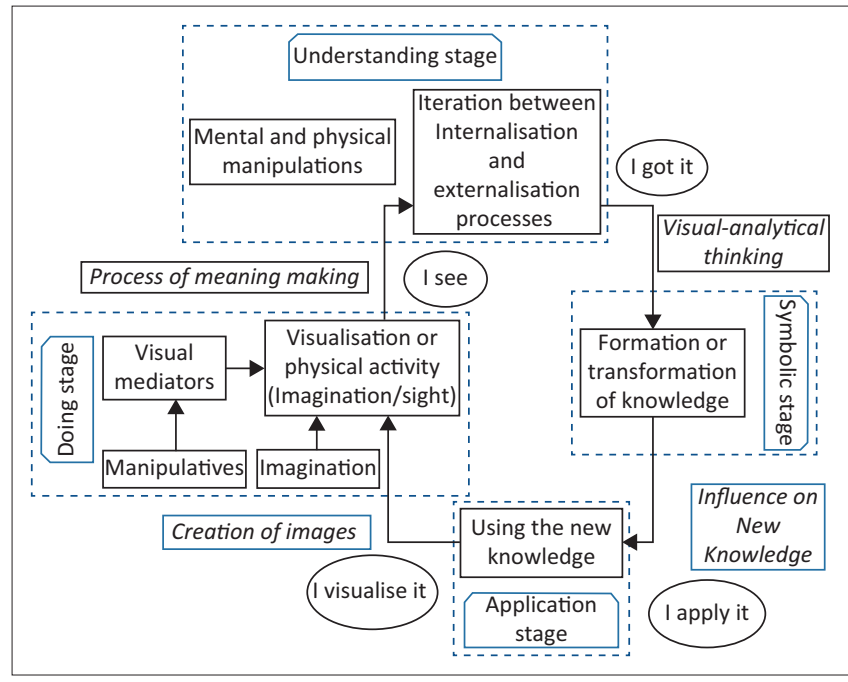

Source: Mudaly, V. (2021). Visualizing as a means of understanding in the fourth industrial revolution environment. In J. Naidoo (Ed.), Teaching and Learning in the 21st Century: Embracing the Fourth Industrial Revolution (pp. 1-10, 53-70). Leiden: Brill/Sense Publishers. FIGURE 1: Iterative visualisation thinking cycle.

\section{Research aim and research questions}

The broad aim of this research was to explore how learners thought about problems and their solutions before attempting to actually write out an answer. In essence, the research question explored how first-year university students responded to simple mathematical problems by getting them to recall their mental activities and processes.

\section{Research methodology \\ General background and sample}

This is a qualitative, interpretivist study of first-year undergraduate mathematics students' use of visuals during a problem-solving activity. The undergraduate class comprised 51 students, generally from poor socio-economic backgrounds. All of the students would have completed 12 years of formal schooling and one semester of university courses, including a module on geometry, which served to reinforce and build on their existing knowledge in order to create more knowledgeable classroom practitioners in the future. All 51 students would have passed a geometry course in the first semester in order to be accepted into the more advanced geometry course in the second semester. The intention of the module is to help the students to employ general principles of mathematics, more specifically geometric procedures for application. The purpose is to develop personal confidence and competence in geometry. This, it is hoped, will prepare teachers for the effective facilitation of learning (teaching) of geometry in secondary schools. All students were invited to participate in the geometry tasks provided. The students were fully aware that this was for research and did not count towards their module mark. Only 35 students volunteered to participate.

\section{Instrument and procedures}

The research was conducted during the coronavirus disease 2019 (COVID-19) pandemic and university shutdowns. All participants were asked to complete tasks that appeared on

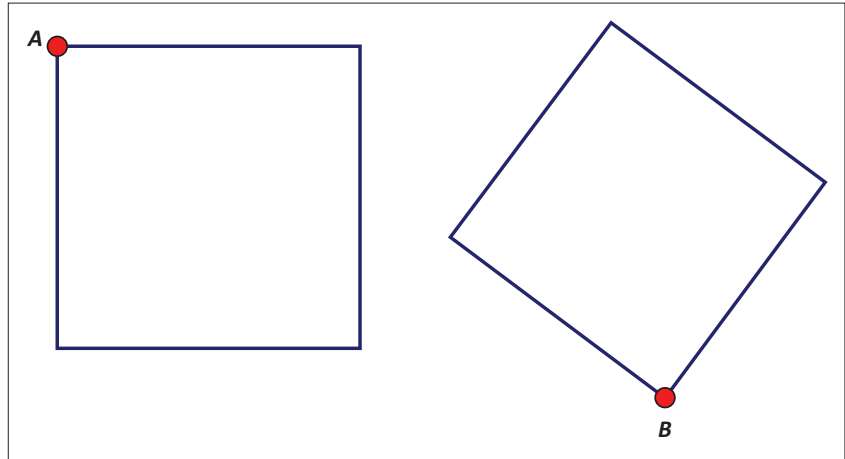

FIGURE 2: Question 1 of the task sheet.

Google Forms. Students were informed that any diagrams drawn could be emailed separately. The interviews were conducted via Zoom or telephone, based on the student responses (needs and availability). The instrument itself comprised 19 questions and each attempted to capture their responses in different ways. In some instances diagrams were provided and in others the students had to create the diagrams themselves.

\section{Data analysis and research results}

The first question that the students had to complete was: What is the value of angles A and B in Figure 2? These types of questions are based on the students' tendency to simply accept properties of a diagram as they see them.

All 35 students reacted to the question by simply looking at the diagram and claiming that the value of angles A and $B$ are $90^{\circ}$ each. This is exactly what was expected. This is obviously a problem with visualisation. Learners sometimes respond quickly to what they see and do not interrogate the details of the given information that may influence the response to the question. Their reason for claiming the angles to be $90^{\circ}$ is that both of the figures were squares ('These shapes are squares and all angles in a square are 90 degrees'). Besides the diagram, no other details were given and therefore the assumption that the shapes were squares was based on their experience of what a square looked like. 'Seeing' without insight is problematic. Overconfidence with knowledge can be dangerous and this is a serious pitfall of visual methodologies.

A similar question was repeated to ascertain the veracity of students 'jumping to conclusions' by simply looking at the diagram. Students were asked to identify the value of A in Figure 3.

Again, 34 of the students confidently stated that the value of angle $\mathrm{A}$ is $90^{\circ}$. Their reasons were all similar: 'Angle in the semi-circle', implying that the angle in the semi-circle is equal to $90^{\circ}$. One student said 'I don't know' because, as he later stated in the interview, he 'could not recall the theorem'. In Figure 2 and Figure 3 the answers seemed to be what they looked like but in the absence of more details, these conclusions were incorrect. Seeing more in the diagram is a common problem and this has to be dealt with deliberately in 


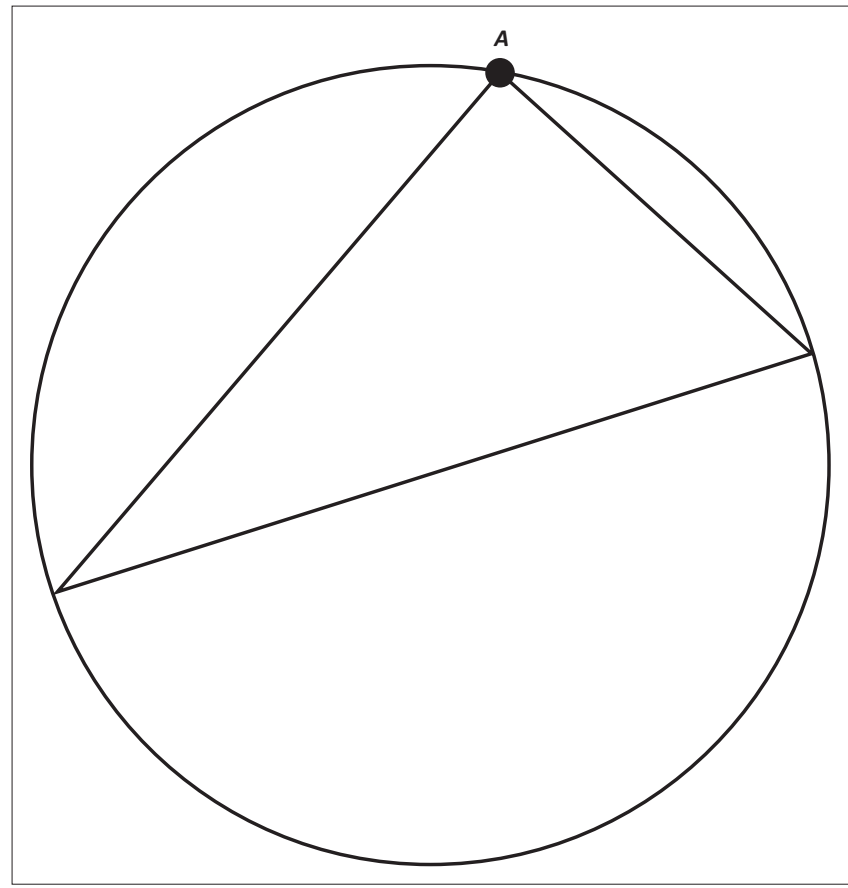

FIGURE 3: Question 2 of the task sheet.

a mathematics classroom. But, these were university students engaging in a geometry module in the second semester of their first year. After having completed all of the Euclidean geometry in the first semester, these 'errors' should not occur. They would have worked through several examples and should have acquired the experience to draw conclusions from what is given and what is assumed. While it can be argued that incorrectly drawn diagrams may result in incorrect conclusions, these diagrams were correct but merely impersonated the students' a priori knowledge of known theorems. This allusion to what students already know creates confidence in their minds.

The responses from the first two questions represented by Figure 2 and Figure 3 illustrates the understanding that the process of visualisation cannot be viewed only as a visual act, something that can be seen with the eyes alone. Visualisation involves sight and insight. Visual mediators and imagination can be used to mentally manipulate mathematical figures, shapes and symbols. In both of these figures the students ought to have considered the properties of the figures by reflecting on what they actually represent. A shape should be defined mentally by its properties. If the properties are not inherent in a figure then the mind should not conclude that that figure is a particular shape. Diagrams (whether mental or physical) cannot be considered metonyms for their properties. A study by Samkoff, Lai and Weber (2012, p. 49) found in their research that 'participants' reasons for using diagrams included noticing mathematical properties'. If the properties did not exist in the diagram then those properties cannot be inserted because they 'looked' like they were there.

Participants were then asked an algebraic question that could be resolved using either mental or pencil and paper methods. The question was: 'The sum of the supplement and

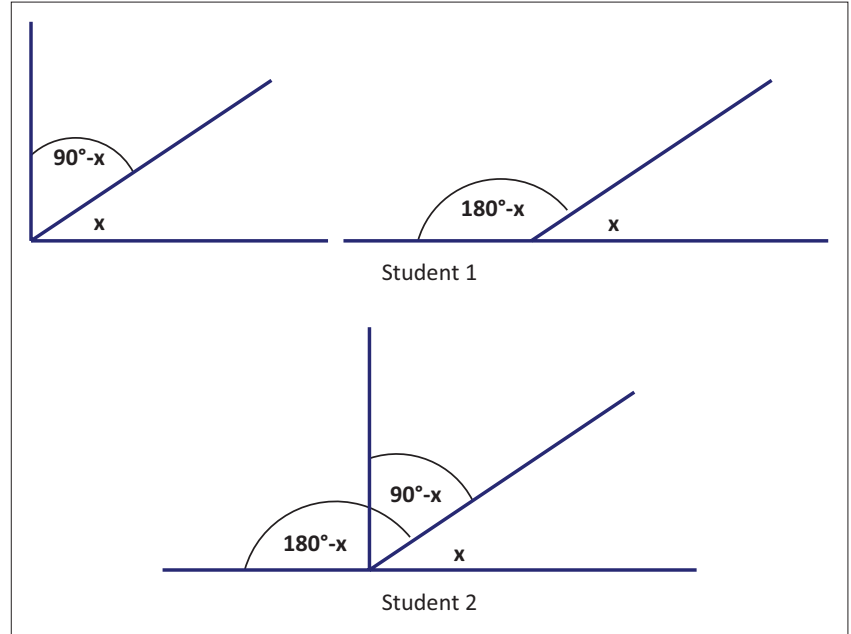

FIGURE 4: Student's drawings - reconstructed using Sketchpad.

the complement of an angle is $130^{\circ}$. Find the measure of the angle. Write out your solution.' The solution to the problem was that the angle is $70^{\circ}$.

Of the 35 students, 9 produced no answer. Their reasons were that they did not know what to do. One student explained that she 'could not imagine what this was'. Eight students were able to provide the correct answer. Three of these students were able to draw diagrams to help solve the problem (see Figure 4) but from a visualisation perspective the other five solutions were of greater significance. The students did produce the correct algebraic solution but when asked how they arrived at the equation $180^{\circ}-x+90^{\circ}-x=130^{\circ}$ (the students used different variables) without using a diagram, one student stated that she could clearly 'see the images in my head, and the expressions were easy thereafter'. Another student also recalled 'trying to imagine the supplement and complement in my head'. There was a particular ease with which these five students translated the question into a mental problem and they mentally manipulated the symbols to produce the equation. This is exactly the process of meaning making. None of the other 18 students could provide a suitable justification for their answers. They seemed to have guessed their solutions and many did not understand the terms supplement and complement. A deep reflection on the results reveals that the students who used a diagram or who claimed to have mentally manipulated the given data were able to solve the problem. Samkoff et al. (2012, p. 50) further concluded that 'diagrams can be used to provide novel and more accessible explanations for mathematical phenomena, or highlight aesthetics that are less accessible through symbols and logic'.

The next question provided a diagram but still required the students to reflect on how they could find the solution. The question required them to determine whether it was possible to find the sum of a, b, c and d in Figure 5 and, if so, what the solution was. The answer to the question was that yes it was possible and the sum was $540^{\circ}$. 


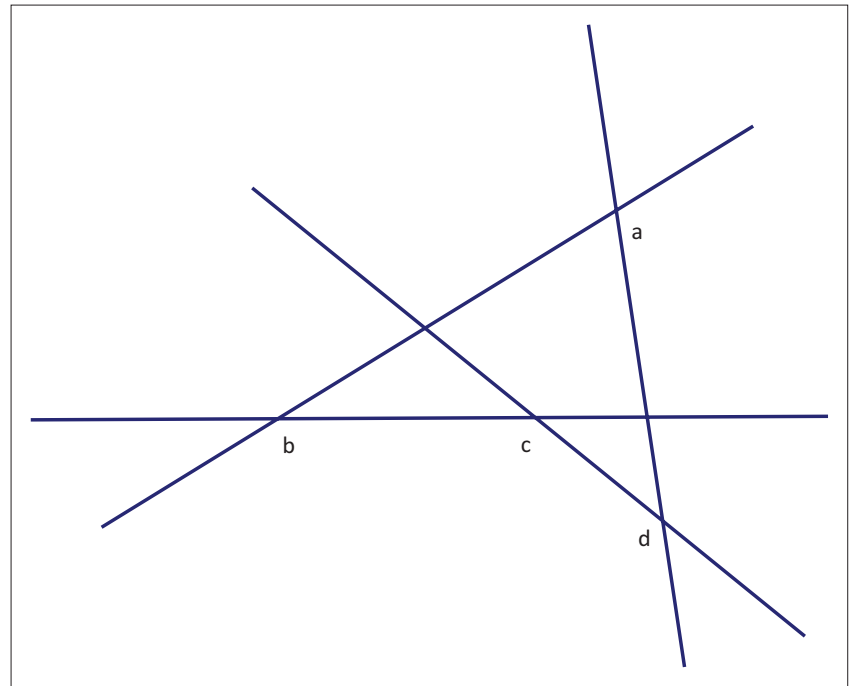

FIGURE 5: The diagram that seems to present little information.

Every student felt that no solution was possible. There was no attempt made to use the different triangles available to seek a solution. When probed about their responses there was a general assumption that no relationships could be found among all four variables. The students were very adamant, when it was suggested that a solution was possible, that 'I cannot see how these letters can be linked to find a solution'. One student stated that 'it can't be found because of some missing information'. Insight requires the students to process the visual data, by using what is given, to create possible solutions. Vision enables us to process the given data at a glance, provided the a priori knowledge can be linked immediately with what is given. A simple iterative process of seeing the different triangles and then noting the angles in terms of these triangles would have guided them towards a solution.

The next question attempted to test their ability to iterate between internal and external processes. They were asked to determine which triangles could be divided into two isosceles triangles and then explain their answers. This required both internalisation and externalisation processes because students had to draw, reflect, redraw and reflect again. This process ought to recur until the students find the correct answer. It seems that there was limited utilisation of the iterative process. A number of students recognised that it could be a right-angled triangle and drew it. Their reflections thereafter produced the hypothesis as stated by one student that 'in the right triangle, a line segment will be drawn from the midpoint of the hypotenuse to the right-angled vertex'. Or the hypothesis that another student arrived at that stated that in the 'right-angled triangle, drawing a line perpendicular to the hypotenuse of the triangle to the vertex of the rightangle, divides the right triangle into two isosceles triangles'. They then proceeded no further. It did not occur to these students that they should reflect on their solution and determine how those new triangles would become isosceles. The iteration simply stopped without any further testing and reflection. But, there were students who first declared that 'the triangle must be a right-angle one'. On further reflection the student stated that 'it must be an isosceles right-triangle which can be divided into two isosceles triangles because two sides are of exactly equal lengths'. While this might not be the complete solution, it did show an added layer of reflection that moved the student's thinking deeper and produced a little more understanding. Even the student who represented his thoughts by saying that it must be a rightangle isosceles triangle ... a line must divide a triangle in such a way that it bisects the right-angle' showed an added layer of reflection. Clearly, the student was close to the solution but he simply did not articulate it well enough. To illustrate an eloquent response to the question one student stated:

'This must be an isosceles right-angled triangle which can be divided into two isosceles triangles by constructing a perpendicular line at the midpoint of the hypotenuse thus bisecting the opposite angle, giving rise to two new isosceles right-angled triangles.'

When asked to explain why she presented more information than was required, the student declared that 'this is exactly how I saw it'. It means that in her mind she could 'see' the segment emanating from the midpoint of the hypotenuse to the vertex of the opposite hypotenuse. She could 'see' that this segment would be perpendicular and it would bisect the $90^{\circ}$ angle. All of this was happening in her mind because she did not draw a diagram. These mental manipulations were deliberate and based on her previously known knowledge.

The proposition that can be drawn from this evidence is that if the students mentally deliberated on the problem, used an iterative process of reflecting on what is given, what is required and what is already known, then there is a possibility that they could find a solution. Some came close in this example but many were very tentative in their responses ('right-angled isosceles triangles, a line must divide a triangle in such a way that bisects the angle').

The responses received for the question related to areas that were mainly well thought of and presented. The question stated that four points are evenly spaced around a circle as shown in Figure 6. Connecting the points makes a square. The diameter of the circle is exactly $5 \mathrm{~cm}$. They had to determine the area of the shaded region and explain how they arrived at this solution.

There were a number of mental knowledge processes that had to occur silently for this question to be answered. Students had to recognise that angles of a square are $90^{\circ}$ (this would then mean that the diameter of the circle is the same as the diagonal of the square), the radius is half the length of the diameter or diagonal,(the side of the square can be calculated by using the Theorem of Pythagoras and the radius of the circle, and the formulae for the area of the circle and the square. There would be various other bits of information that the mind must recall, such as calculations, symbols, notations, procedures and concepts (like area, for example). 


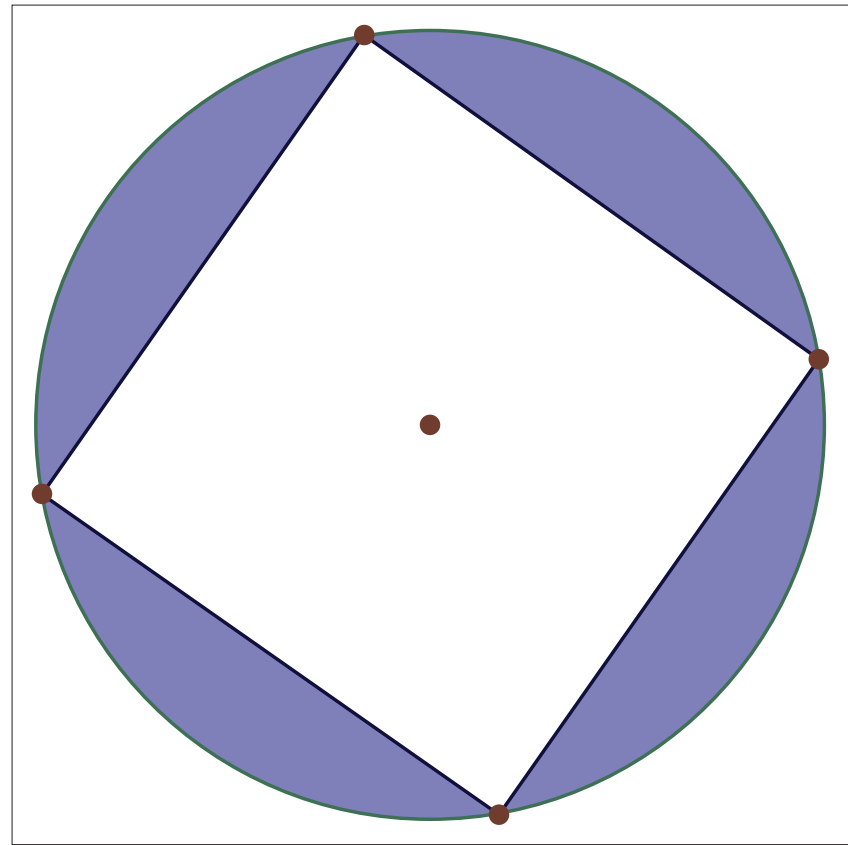

FIGURE 6: Areas of circles and squares.

This is a large amount of information to process at one time but through practice and engagement, this becomes easier. The students were able to explain their mental procedure by saying:

'Find radius which is 2.5. Use the Pythagoras theorem to find the length of the side of the square. The shaded region is the difference between the area of the circle and the square.'

While none of the subtle processes are described, they are inherent in the response. To get the radius, the student knew that the diameter was $5 \mathrm{~cm}$. By calculating the side of the square, the student recognised that the diameter and the diagonal were the same. These become part of the known knowledge and can be 'seen' at a glance.

The next question sought to understand the students' thinking when they are faced with problems that require solutions that are not immediately discernible from the question itself. The data collected did not seek the solution itself but delved deeper into the way the students were thinking. The question itself was:

'In a quadrilateral two angles are equal. The third angle is equal to the sum of the two equal angles. The fourth angle is $60^{\circ}$ less than twice the sum of the other three angles. Find the measures of the angles in the quadrilateral.'

Before they could solve the problem, they were asked the following set of questions:

- When you read through this problem, describe exactly what happened in your head. Give as much detail as possible.

- When you see a problem such as this one, list the sequence of activities you engage in, in order to solve it. What do you really do?

- What do you consider to be the most important part in this solution process?
These questions were important in order to understand how students first react to problems and what they actually think and do during the problem-solving process. So, they were given the problem and were then asked to answer the questions below.

\section{When you read through this problem, describe exactly what happened in your head: Give as much detail as possible}

There were various responses to this question but they generally captured the idea that the students created mental images and manipulated these images to firstly understand the problem and then find the solution. One student stated that in his head he tried 'to construct the figure and to guess what could be the angles'. Another student related her experience by saying that she found:

'the first three angles easily but the fourth angle I found it difficult to understand mentally. It then came to my mind that I have to write down the sizes of all the angles so that I will arrive at the answer.'

She was alluding to an internal and external process. A number of students indicated that their first reaction was to visualise the diagram. These are examples of student responses:

I instantly visualized the problem and tried to picture what kind of quadrilateral it could be.

An image of a quadrilateral was visualized, then I started to add each bit of information to that quad.

I drew a diagram in my mind and I talked to myself.

Automatically the structure appeared in my mind, all information was stored together

There is sufficient evidence here to show that the students' initial reaction was to create mental images and then try to fit the given information into that image. Some students simply began by drawing a physical diagram: 'I took the pen and drew a 4-sided figure and put the labels A, B, C and D on the vertices and named the 2 angles as UNKNOWN " $x$ ".

In all of these cases an image played a crucial role in the solution.

\section{When you see a problem such as this one, list the sequence of activities you engage in, in order to solve it: What do you really do?}

The general practice was to draw a diagram from the information that the mind had processed and then to fill into the diagram the given information. Other students would begin by underlining the key words in the problem so that they could focus on the key words and concepts directly when attempting the solution. One student provided clear details by saying:

'After thinking and drawing my diagram, the first thing I did was to let the two equal angles equal to $x$. I used that to find the other angles in terms of $x$. I added the angles of this quadrilateral and equated them to $360^{\circ}$. Then I solved for $x$. Once I found the value for $x$, I solved for each angle.' 
Another student indicated that he would:

'read each sentence individually. Then draw a rough sketch. Then start filling in information which tells me what I have and what I need. Then proceed to get the information I need. Then solve.'

The common theme in the process of solving was to draw a diagram and then enter the given information into the diagram ('You consider how many angles/sides you are given and draw the figure such that everything you are told in the statement appears in your figure'). There is a reason for inserting all the information into the diagram. It seems that their mind processes the information together when they look at the diagram. A trained mind can pick up all the information at one glance like Sherlock Holmes who would look at a crime scene and have a fairly good idea of what transpired. This comes with practice.

\section{What do you consider to be the most important part in this solution process?}

Still intent on probing the students' thought processes, the next question asked what they considered to be the most important part in their solution process. This question also evoked a myriad of responses. Many indicated that reading the question carefully was important; others felt that understanding the question was crucial. Only seven students felt that drawing a diagram was most important. When other students were probed about not finding the diagram to be important some replied:

But I already had the diagram in my head.

This was easy to see.

The image was already determined.

Thinking came with the diagram.

I did not need to draw, it automatically appeared in my mind.

All of that happened inside here [tapping the head].

All of these responses pointed to the fact that visualisation played a central role in the problem-solving process.

The next question sought to establish the mental conversations they engaged in with themselves.

The exact details were not conclusive but a few examples are provided. One student stated that his internal conversation contained questions such as: 'What figure am I working with? Will this figure give me correct answers? Does this figure include all aspects of the statement given? Can I use $x$ as a variable?' These are just some of the questions that he asked himself. Another student indicated similar thoughts: 'What information is given? What do I need? How do I draw this? What is required of me to solve this problem?' A third student's mental conversations reflect the following thoughts: 'Can I find two unknown angles? I can make one of them equal to $x$. Sum of angles of a quadrilateral is equal to $360^{\circ}$. I can add all angles and those will equal to $360^{\circ}$.

These conversations seem to concentrate on what they have, what can they do and how they could manipulate the information given. Much more needs to be done in this area.

\section{Discussion}

The evidence shows that while visuals are important in mathematics, they must be used appropriately and in conjunction with previously acquired knowledge. Overconfidence in drawing conclusions too quickly from illusory diagrams poses a problem. Students must be taught to explore what is actually given in the context of the visual. The words in the problem must harmonise with the diagram given or created physically or mentally.

The second finding shows that if students draw diagrams in order to solve problems then they are likely to solve the problem. There are two possible reasons for this. In drawing the diagram deeper meaning is extracted from the problem itself. If the problem is better understood then a solution is likely to be found. The second possibility is that diagrams provide a global picture of the problem which can be mentally manipulated by the student in order to explore different possibilities quickly. This is akin to using computer software to produce many examples in a short time unlike when using pencil and paper methods.

The third finding relates to the way students attempt to link given information to previously learned mathematical knowledge. If the link is not explicit, students struggle to see the connection. They are able to manipulate images in their minds but often they do not extend themselves far enough to see new possibilities. This was evident when they could not determine which triangles could be divided into two isosceles triangles. They were getting close to the solution and with a little more reflection they probably would have found the solution, but they would just stop without exploring the problem further.

\section{Conclusion and implications}

The final finding gave us a glimpse of the conversations that some of the students had with themselves. There was an indication that these students devised plans in their heads, organised their information in their heads and worked towards a solution in their heads. But, most importantly, they constructed and transformed diagrams in their heads. They were able to form pictures in their minds before they could draw them on a page. In some instances they were seeing the solution before writing the solution.

Despite this finding, it was evident that many students were still hesitant to draw physical diagrams or even formulate one in their minds. This is similar to Samkoff et al.'s (2012, p. 50) declaration that 'researchers have noted that students are often reluctant to use diagrams, even for problems where their use might be highly productive'. There is probably a lack of practice in the use of diagrams and this probably stems from the underusage of this heuristic tool when solving problems in school. Cooper and Alibali (2012, p. 281) argued that 'many studies also suggest that the usefulness of visual representations depends on students' ability levels'. 
While this may be the case, I believe that practice and prior knowledge are key factors.

With the increasing use of technology, diagrams become an even more priceless tool. Jones (2013) found that:

diagrams are invaluable in aiding the teaching and learning processes; it is also clear that the processes involved in using diagrams are surprisingly complex this points to the need for more research into diagrams in the teaching and learning of geometry. (p. 41)

Perhaps, we need to acknowledge that diagrams are critical in the learning process because they offer great prospects for establishing understanding as the student engages in commognitive discourses with the self. In thinking and reflecting, meaning can be extracted from physical or mental images.

More research must be conducted to explore the relationships between the students' creation of mental and physical images, the way they communicate these ideas with themselves and how this leads to deeper understanding.

\section{Acknowledgements \\ Competing interests}

The author declared that no competing interest exists.

\section{Authors' contributions}

I declare that I am the sole author of this research article.

\section{Ethical considerations}

All the necessary ethical considerations were included in our application through the ethics office at UKZN.

\section{Funding information}

This research received no specific grant from any funding agency in the public, commercial or not-for-profit sectors.

\section{Data availability}

Data sharing is not applicable to this article as no new data were created or analysed in this study.

\section{Disclaimer}

The views and opinions expressed in this article are those of the author and do not necessarily reflect the official policy or position of any affiliated agency of the author.

\section{References}

Chi, M.T.H. (2008). Three types of conceptual change: Belief revision, mental mode transformation, and categorical shift. In S. Vosniadou (Ed.), Handbook of research on conceptual change (pp. 61-82). Hillsdale, NJ: Erlbaum.

Cooper, J.L., \& Alibali, M.W. (2012). Visual representations in mathematics problemsolving: Effects of diagrams and illustrations. In L.R. Van Zoest, J.-J. Lo, \& J.L. Kratky (Eds.), Proceedings of the 34th annual meeting of the North American Chapter of the International Group for the Psychology of Mathematics Education. Kalamazoo, ML: Western Michigan University. Retrieved from https://files.eric.ed.gov/ fulltext/ED584910.pdf

Gutiérrez, A., Ramírez, R., Benedicto, C., Beltrán-Meneu, M.J., \& Jaime, A. (2018). Visualization abilities and complexity of reasoning in mathematically gifted students' collaborative solutions to a visualization task. A networked analysis. In K.S.S. Mix \& M.T. Battista (Eds.), Visualizing mathematics. The role of spatial reasoning in mathematical thought (pp. 309-337). Cham: Springer.

Guzman, G.M. (2018). Mathematical problem-solving strategies among student teachers. Journal on Efficiency and Responsibility in Education and Science, 11(3) 53-64. https://doi.org/10.7160/eriesj.2018.110302.

Ibrahim, B., \& Rebello, N.S. (2013). Role of mental representations in problem solving: Students' approaches to nondirected tasks. Physical Review Special Topics Physics Education Research, 9. Retrieved from https://journals.aps.org/prper/ pdf/10.1103/PhysRevSTPER.9.020106

Jones, K. (2013), Diagrams in the teaching and learning of geometry: Some results and ideas for future research, Proceedings of the British Society for Research into Learning Mathematics, 33(2), 37-42.

Mudaly, V. (2021). Visualizing as a means of understanding in the fourth industrial revolution environment. In J. Naidoo (Ed.), Teaching and Learning in the 21st Century: Embracing the Fourth Industrial Revolution (pp. 1-10, 53-70). Leiden: Brill/Sense Publishers.

Presmeg, N.C. (1986). Visualisation in high school mathematics. For the Learning of Mathematics, 6(3), 42-46. Retrieved from http://www.jstor.com/stable/40247826

Rösken, B., \& Rolka, K. (2006). A picture is worth a 1000 words - The role of visualization in mathematics learning. In J. Novotná, H. Moraová, M. Krátká, \& N. Stehlíková (Eds.), Proceedings 30th Conference of the International Group for the Psychology of Mathematics Education (vol. 4, pp. 457-464). Prague: Charles University.

Samkoff, A., Lai, Y. \& Weber, K. (2012). On the different ways that mathematicians use diagrams in proof construction. Research in Mathematics Education, 14. Retrieved from https://www.tandfonline.com/doi/pdf/10.1080/14794802.2012.657438?ca sa_token=INukq1NTTXkAAAAA:U6rYUoA6yT9_MEAV9ezDFfiljdxPYGiwQ2hYYX Kvt3DHKOHU4yYKEjZckfIMr4KgWTKL8cksTzyHzbE

Tambychika, T., \& Meerah, T.S.M. (2010). Students' difficulties in mathematics problem-solving: What do they say? Procedia Social and Behavioral Sciences, 8 , 142-151. https://doi.org/10.1016/j.sbspro.2010.12.020

Vale, I., \& Barbosa, A. (2018). Mathematical problems: The advantages of visual strategies. Journal of the European Teacher Education Network, 13, 23-33.

Yin, S.H. (2010). Seeing the value of visualization. SingTeach, 22(Jan/Feb), 1-8.

Walker, C.M., Winner, E., Hetland, L., Simmons, S., \& Goldsmith, L. (2011). Visual thinking: Art students have an advantage in geometric reasoning. Creative Education, 2(1), 22-26. https://doi.org/10.4236/ce.2011.21004

Whiteley, W. (2004). Visualization in mathematics: Claims and questions towards a research program. Paper presented at the 10 International Congress on Mathematics Education. Copenhagen, Cambridge: Cambridge University Press. Retrieved from http://www.math.yorku.ca/ whiteley/Visualization.pdf 